\title{
Performing Online and Offline: How DJs Use Social Networks
}

\author{
Mayur Karnik, Ian Oakley, and Valentina Nisi \\ Madeira Interactive Technologies Institute, University of Madeira \\ Campus da Penteada, Funchal, Portugal \\ \{mayurkarnik, ian.r.oakley, valentina.nisi\}gmail.com
}

\begin{abstract}
Music and online Social Network Sites (SNS) are closely intertwined in popular culture, but we know relatively little about how performers use and take advantage of such social systems. This paper investigates this space by exploring how professional DJs leverage SNS in their work. It adopts a long term mixed-methods ethnographic approach encompassing semi-structured interviews, supported by studio visits and participant observations. Results revealed that DJs used SNS for connecting to their audiences; promoting their work; receiving peer feedback; discovering content and keeping abreast of their field; and organizing and coordinating events. We further interpret our findings in the context of issues DJs highlighted about their professional practice and technology, and our observations; and draw out design implications for future music orientated systems and services.
\end{abstract}

Keywords: Ethnography, DJs, social networks, participant observations.

\section{Introduction}

Social Network Sites (SNS) are a key part of the success of modern performance artists, helping small or emerging acts connect with fans, advertise their shows and provide access to their media [1]. Rapid growth in SNS usage along with technological advancements in computational power, mobile technologies and network bandwidth, present these artists with new opportunities and challenges. For example, unlike in the past when music artists were relatively inaccessible to fans and media, today they directly seek engagement with their fans and patrons using a number of channels available through SNS [2]. Indeed, MySpace, one of the earliest SNS to achieve popular critical mass is strongly associated with its role as a platform for bands to promote themselves [3]. Conversely, music audiences today use multiple and inter-linked sites online, reflecting the changing 'shapes' of online communities [4]. It comes as no surprise, therefore, that the most watched and liked content on YouTube today belong to musical phenomena such as Justin Bieber and PSY (Gangnam Style) [5], both arguably products of a fame that has been powered largely by social media (e.g. in the form of tribute videos). Easy access to technologies aimed at content creation and distribution has popularized the technique of 'micro-celebrity' $[6,7]$, which is the practice of using social media to develop and maintain an audience. 
Furthermore, a growing ecosystem of companies is beginning to provide dedicated social software tools to help performers understand, maintain and manage audience interactions [8]. However, despite the prevalence and importance of this issue for performers, there has been relatively little academic work studying the needs and practices involved in this user group's adoption and appropriation of social technologies. This paper aims to address a specific area of this gap by describing a mixed-methods ethnographic study of a group of resident DJs. The study focuses on their use of technology in their everyday lives, and in particular to their professional use of SNS.

We argue that DJs, solo performers who participate in an almost inevitably local and heavily technology driven popular art form, are a particularly interesting user group for this study. We focus on DJs for a variety of reasons. Firstly, we observe that DJs, with their electronic and digital instruments, have a more direct and deeper engagement with technology, as compared to traditional musicians or bands. Secondly, DJs have to constantly depend on social engagement, not only offline with their audience during their performances [9], but also online with other DJs and for promoting their work in order to build and maintain their profiles as artists [10]. Thirdly, DJs rely on discovery of music to feed their work rather than the more traditional creative and individual activities that other types of artists typically engage in. Furthermore, they need to be sensitive to trends, styles and techniques not only in a single genre, but across a range of types of music, as required by the different gigs they play; thus implying the need to be externally focused and engage with a range of different communities to stay current. These characteristics make DJs an interesting and important group to study in order to explore the socio-technical gaps in the context of artists. Studying such a tech-savvy and socially active segment of artists can have wider implications for our understanding of the social aspects of music [11], and further lead to insights into the wider HCI issues faced by artists and cultural workers.

This claim is supported by the richness of activity captured in Ahmed et al.'s [10] recent ethnographic study of DJs at work, that highlighted the overall complexity of the work practices, which go considerably beyond performance to encompass activities such as collecting and collating musical libraries through to preparing specific gigs and set pieces, to engaging in intensive publicity and promotion. They briefly touch upon the role of SNS in a DJ's promotional activities and highlight some of the issues that SNS present. However, we argue for a more in-depth examination of DJs' use of SNS through an understanding of their motivations for using SNS and the concomitant challenges. The current paper thus extends their insightful analysis with an exclusive focus on, and a more detailed study of, the role of social networks in the work of DJs.

In sum, the goal of the paper is to provide a deeper understanding of the role of SNS in a DJ's everyday life. It is structured as follows: a brief overview of related work; description of mixed-methods employed towards a long-term study of a small community of DJs; a description of the findings, focusing particularly on the motivations for SNS use and issues germane to their practice; followed by a discussion leading to design implications for future music orientated social systems. 


\section{Related Work}

Music plays an active role in the construction of our everyday social lives [12]. It lends us means to express, understand and share our identities [13]. Tanaka [14] argues that social computing coupled with artistic creativity can point out 'ways in which technological evolution can be assimilated directly in cultural production, ultimately leading to possible new forms of musical content.' Drawing on Goffman's seminal work on social interaction [15], he compares early conceptions of humanmachine interaction with musical ensemble performance and suggests that music, as a cultural practice, has the potential to contribute to a deeper understanding of interaction [14].

HCI researchers have described a number of studies of, and systems for, the DJ community. Spurred on by the advent of the Internet, smartphones and the digitization of music, early research in this domain focused on tools and audiences. Gates et al. [9] classify these initial works as interactive nightclub technologies that were essentially audience-centered applications, DJ-centered applications, and applications for interaction between the DJs and their audiences. These applications broadly attempted to take advantage of sensors, mobile devices and communication technologies. They took the form of playful applications, performative spaces, automation and mixing tools, and systems based on bio-feedback [9]. Ahmed et al. [10] present an overview of more recent studies and prototypes that employed a variety of modalities (e.g. wireless, mobile, haptic, and multi-touch) but were mainly limited to the nightclub setting.

More recently, however, researchers have begun focusing on ethnographic approaches in order to understand the DJs' overall context of work. Gates et al. [9] focused on how DJs gathered information about, and interacted with their audience in nightclubs, while Ahmed et al. [10] give a detailed account of how the DJ's work extended beyond performance to include 'the work to make the performance work': collecting, preparing, performing and promoting. They found DJs to be active on several SNS and forums in order to promote themselves and acquire bookings, but faced general challenges in integrating these activities. Many more traditional social aspects of SNS were reportedly viewed with suspicion - basically as a source of biased (universally positive) feedback from fans.

This viewpoint is counter-intuitive - SNS have a long history as a tool for performers to reach audiences. For instance, the early success of MySpace was strongly linked to its role as a platform for bands to promote themselves and engage with their fans and audience [3]. Beer argues how the presence of the musicians catalyzed social connection amongst fans on MySpace [16]. Sargent [17] carried ethnographic studies of local musicians in Charlotesville and found that active social networking was crucial to their music distribution and promotion. Her studies demonstrate how musicians cultivated audiences through social capital both online and offline. Music fans have been found to use multiple and multi-linked network sites as Baym's early work on Swedish independent music fans demonstrates [4]. More recently, Baym explored online music audiences from the perspective of the artists and presents a rich overview of research on fans and fandom [2]. Similarly, Marwick and boyd [7] 
discussed how social media is utilized by public figures to maintain the practice of celebrity despite the underlying power tensions of these interactions. Researchers have proposed online systems that enable DJs to broadcast their work [18] and shown ways in which the activities of performers rely on digital resources and social networks [19]. Furthermore, Facebook, the currently dominant SNS, recently launched a 'listen' feature that enables performers to easily share content from their pages [20]. On the other hand, Ping, a music-based SNS from industry heavyweight Apple, recently announced its closure [21]. The diversity of these experiences and features suggest that the interaction between performers, SNS and audience is complex, multi-level and poorly understood.

The remainder of this paper aims to contribute to understanding of this issue by presenting an ethnographic study of a small community of DJs, with a specific focus on their use and engagement with SNS.

\section{Methods}

A mixed-methods approach was adopted in order to develop a nuanced understanding of the social milieu of a DJ's everyday life. This comprised of 1.5 to 2 hour semistructured interviews conducted with 6 DJs supported by six to eight observational site visits to the clubs and environments in which these DJs performed and four visits, each spanning three to four hours, to the personal home studio of one of the DJs. Taken together, these activities allowed the capture of a detailed picture of both the private and public environments in which the DJ's work took place. Additionally, as part of a process of participant observation [22, 23], the primary author of this paper took on the role of an apprentice or amateur DJ / VJ and performed several gigs with three of the DJs over a period of one year. This extent of participation was motivated primarily by the need to get a closer access to an otherwise inaccessible group and secondarily owing to the primary author's own interest and experience in audio-visual performances. These activities are unpacked and described in detail in the following sections.

\subsection{Semi-structured Interviews}

The interviews were conducted between March 2012 and June 2012 with a representative group of six DJs working in Funchal, a small and relatively isolated city (approximately 150,000 residents). Five held residencies, or permanent performance arrangements, with major local clubs. Aged between 27 and 35, their professional experience spanned six years (three individuals), ten years (one individual) and 17 years (two individuals). They were also highly engaged with the wider aspects of musical culture - three authored or produced music while one had previously owned a record store and served as a partner in a small record label. They were not provided with compensation for their time. 
The semi-structured interviews explored three questions:

- What were their daily routines like in the week and during the weekends?

- What technological artifacts did they use, personally and professionally, in their day-to-day lives and why?

- What social networks did they use, why and how?

At the end of the interview, respondents were encouraged to make more openended comments. The interviews led to more than 10 hours of data and were transcribed verbatim. In line with Hook et al.'s [24] process, the transcripts were then subjected to Thematic Analysis [25].

\subsection{Studio Visits}

One of the DJs volunteered to participate in a more in-depth study. Two visits were made to his home studio, followed by visits to his work sessions at his resident nightclub, followed by further two visits to his home studio. This process was conceived to provide detailed insights into his full workflow, studio environment and the overlap between his personal and professional life. Photos and videos were taken during these sessions for later analysis. Care was taken to keep these recording activities discrete to ensure it had minimal interference or influence on behaviors.

\subsection{Participant Observation}

Overt participant observations of the DJs, conducted with informed consent, were made periodically over a one-year period. These observations took place at performance venues and spanned a full range of work activities: preparing, warming up, performing and transferring the decks to a follow-up act or retiring for the night. The observations were recorded through photos, videos and notes. These observations were further supported by club owners who provided weekly images (through their Facebook Pages) for a period of several months. Extending these efforts, the primary researcher adopted the role of an amateur DJ / VJ in order to connect with the community, gain a deeper understanding of the performers' context and engage more empathetically with the participants and their roles. Such truly participatory observation is a valuable and established part of ethnographic practice. In this case, it involved making seven performances (four as a DJ, three as a VJ) in different venues with three of the DJs over a period of one year.

\section{$4 \quad$ Findings}

The interviews were transcribed and subjected to a process of inductive Thematic Analysis [25] using TAMS Analyzer, an openly available qualitative analysis software tool. A list of meaningful units were extracted from all the transcripts and subjected to an inductive coding process, resulting in a list of 85 codes. These codes were further clustered and organized into different categories that reflected the 
various subjects that the respondents talked about, for example SNS, performances, routines, personal time, etc. Owing to the focus of the study, SNS emerged as a higher-level category and we further scanned through these items and extracted insights that comprised of motivations for use and challenges encountered.

In the results section below, we first summarize and discuss these insights, giving particular attention to data about SNS, in conjunction with insights from our participant observations. Due to the scope of this paper, we limit our reporting of our observations to the social dynamics embedded in their work environments.

\subsection{Routines}

As expected, the routines of DJs differed for weekdays and weekends. While weekends were reserved for performing at their respective club venues, weekdays were characterized by social life, leisure and secondary work activities such as searching for new content, making music, preparing gigs and networking. Weekend work routines typically started and finished late, causing a sleep pattern that extended to their entire week. Owing to these erratic patterns, the DJs adopted ad-hoc routines through the week, moving between preparing for weekends and producing music; reflecting an inclination to maintain flexibility necessary for a creative profession.

MC: "So I dedicate lots of time researching the tracks to get music... and then it really depends on my mood because I make music as well. Some days I am not feeling particularly inspired. So I dedicate my day to research only... some other day I wake up and think I am going to make music, so I will dedicate my time (only) to that."

However this would often lead to frustration over a perceived lack of control and consequently to attempts at getting more organized.

FL: "Because I work at night, my sleeping schedule is a little bit... I don't know... a bit different, mixed up. I work on the weekends, but on the daily weekdays I simply cant just go to bed at midnight... I can't I can't! I just can't sleep... I sleep at 2 or 3 in the morning, that's the best I can do."

G: "I used to wake up at 3 o clock in the afternoon, but now I learnt to wake up at 8."

\subsection{Artifacts}

A wide variety of artifacts were used in work. Many were technological; all the DJs performed with computers and used various storage media (CDs, memory sticks, hard-drives) to host their music. Dedicated accessories (turntables, mixers) were widely used to control and access their digital libraries. Smartphones were used for communication (mail and SNS) and several participants also used music identification apps. Overall, DJs exhibited a high rate of acceptance to changes in technology as far as professional equipment was concerned. They appreciated the inter-operability of this equipment and particularly its easy integration with laptops via modern software applications catering directly to the tasks of live performance and music production. 
F: "I work with Abletone live... you can connect with various plugins, USB, you can get VHC; it's a world of music, an elephant!.. I have MIDI controller which is from M-Audio. I have all the DJ components... I use Traktor; last year I bought Traktor Controller S4 deck.. which you can connect with your computer and play which is great."

MC: "I used some samplers in the past. When I was playing vinyl or anything, I could record live what I was playing... like a short loop and would remix it live. If you have a song, you could transform it, remix it... if there was some part the crowd liked, I could record it and then play it over at the end of the show just to get a little creative. I used to use it like that. But as things were changing, there were new programs designed for playing for DJs... like Tractor, Native Instruments... there were programs where we could use MP3 to play. So I made this change 3 years ago. I use Traktor from NI and I use my Macintosh, my Mac Book. I have all my music so I connect my hard drive where I keep all my music."

Respondents valued the practical performance related aspects of digitization of music and the attendant miniaturization of media formats, offering benefits such as portability, convenience during travelling for performances, and a higher degree of control over their planning.

$\mathrm{H}$ : "5-6 years ago to go to a gig to [xx city] I had to carry 25 - 30 kilos of music. And then in the plane you can only take 20, every time you go you have to pay extra... with vinyls sometimes you arrive there, the bag doesn't arrive... the bags disappear and nowadays I can go only with my laptop, with few vinyls and it's done. These days, with ten kilos you can make a party."

M: "I carry also my Macintosh everyday because I have my projects, my music, my plans all inside my Mac. When I go for gig, my Macintosh. I don't carry music physically, I don't carry CDs or vinyls, I play with computer, Traktor... I don't like to carry a lot of things. I am very practical; I don't need a lot of things. I can give you an example; if I go on a trip, I carry light, pack light... two pairs of shoes, two pairs of trousers, two pairs of $t$-shirts."

Social networks and peer communication had distinct associations with artifacts, with one respondent describing how friends he knew solely through social networks helped him not only in recommending a new equipment but also by buying and shipping it to him. Another respondent described at length an array of networking related apps that he carried on his smartphone. Almost all the respondents, barring one, owned smartphones and used the same for emails, social networking and social media consumption.

F: "I like to share (about) new stuff, new hardware stuff with my friends... and they share as well; for example, I bought my keyboard via Internet... from some guys in Berlin; they ordered for me, that's the advantage of social network."

FL: "I work with a computer and software applications. I work with that and I have lots of music. If I play it all together, I will play for 5 or 6 days... I have a Blackberry with some apps for text messages, battery status... a player for YouTube, a chat for Facebook, Shazam the music guesser... the one that I really use is the Blackberry messenger, we can chat with $B B$ community for free." 


\subsection{Motivations for Using SNS}

The DJs used social networks extensively for both personal and, primarily, professional reasons. All had accounts on Facebook, SoundCloud and Resident Advisor while 4 used Mixcloud, 2 used Twitter and 5 had, largely inactive, MySpace accounts. As local celebrities, they reported high numbers of friends on Facebook with a large fan base supplementing typical cohorts of family and "real" friends. Indeed, three of them maintained two or more Facebook accounts and four ran their own Facebook Page.

Our study reveals that DJs used SNS for interaction and connection, promotion, feedback, discovering and learning, and for organizing and coordinating events. A detailed discussion of their use of SNS is presented below.

Interaction and Connection. DJs used social networks to communicate with two specific groups: local fans and regular club patrons; and a set of remote artists, performers, fans and potential promoters in other cities or countries. This second activity, perhaps due to a lack of other channels to achieve it, was viewed as having higher value.

FL: "First of all I want to share (my music) with people here in [city]... my first priority. I put them on my Facebook or [club]'s Facebook and the second objective is... it's the world of course, because I am on an island I have to reach the people that are outside this island."

DJs highlighted how they differentiated between fans and friends on their social networks. Fans were often courted through the DJs releasing their own content (either novel tracks or mixes) online or via recommendations and endorsements of other artists or songs. The DJs largely perceived these activities as part of a responsibility to educate and expose their audience to high quality new music.

H: "On Facebook I have 50\% people I know, others who know my work or know someone who knows my work or simply so many times it happens, you post a YouTube video or a set I made... 20-30 guys and add me only for that because they identify themselves with that... ok this guy to be my friend. At the end of the day, this thing of Facebook friends its not like... the friends word is not right, its not friends... It's people who have same interests... the starting engine of friendship maybe, but not friends."

FL: "The videos I upload on my Facebook through YouTube is to show the people some good music and try to teach them, because the nightlife and clubbing are a little bit of weird than what it used to be... the people don't have the feeling they had a few years ago."

They also engaged in post-performance dialogues with audience members where they exchanged (almost universally) complements and tagged and commented on posts or photos. One DJ, however, pointed out how, on the downside, SNS also sometimes enable performers with better public relation skills to be more popular than the ones with talent. 
MC: "Before you had to 'do' something for people to like your work or you had to have great music that nobody else had... Or you had to be a really good selector or a really good mixer... but now you need to be... well, if you are a good public relation guy, you don't need to have talent or anything. It's just a bit annoying sometimes."

DJs used dedicated features of music-centered SNS (e.g. SoundCloud) to share music and interact with performers playing in similar genres; exchanging content with peers was commonplace. SNS messaging complemented these media focused activities. One DJ noted that the widespread use of SNS has fostered and simplified a vibrant culture of "remixing" where DJs receive, reinterpret and re-release each other's content.

F: "These days we are getting more and more remixes on the track because of the interaction of the people on the sites... DJs... these days you can make music, put it online and then share with other side of the world to make remix... ten fifteen years ago, we were listening to only single and original tracks... there are more remixes... its about the technology that allows you to share and collaborate with other artists."

Promotion. The DJs valued SNS for promoting their work; such digital activity was reported to have simplified, reduced the cost of and, ultimately, replaced previous approaches such as distributing flyers or demo CDs. Specific activities they engaged in included posting flyers and schedules; maintaining shared music charts (on sites such as Resident Advisor) to showcase and recommend their work; and posting or linking to their media across a wide range of SNS services. Some of the older DJs had moved from music oriented SNS like MySpace to more generic ones like Facebook due to higher visitor traffic. Two DJs used the Facebook "Listen" feature [20] on their pages on that site and others shared content via third party plugins (e.g. Bandpage and MixCloud).

M: "I used MySpace in the beginning, like 6 years ago... I used it a lot. Now I go there like once in a month. I put my gigs and not too much. I don't put too much information. Now I am using more Facebook. I have my 'Bandpage' and it works better than MySpace. I see the statistics from the page... like at MySpace after 6 years I have like 4000 or 5000 visitors, its what I have per month on Facebook. It's different."

However, beyond these commercial services, some of them highlighted the importance of being present in other communication channels, for example most of them talked about the value of a personal web presence carrying a biography, schedule, sample media and collecting together all SNS contact details. Furthermore, four DJs played regular sets on local radio stations and one on a well-known Internet radio station (Proton). To support these activities, the DJs reported distributing podcasts of this material. Indeed, two reported broadcasting their work immediately after finishing a set using recording tools integrated into SoundCloud. Their need to cross integrate profiles and content between traditional channels on the Internet and social networks was quite evident in their responses. 
Feedback. The DJs all reported that feedback on their work was a key motivation for using SNS. Detail, granularity and feedback from peers were especially valued. For instance, SoundCloud a pro-service that enables site visitors to comment on specific instances of a track was repeatedly praised. Often these comments would be made by other professionals in the form of suggestions about how the track could be improved.

H: "On SoundCloud, you can have feedback in the very 'second' they like and sometimes its good if you have some work-in-progress some tracks... and the guys can say oh its good but over here you can change... you go to the studio and ok he has a good point of view, lets make this change."

One DJ mentioned how he looked up the profile pages on SoundCloud to assess whether commenters on his material were "qualified" to provide a worthwhile critical opinion. Feedback from fans on sites such as Facebook, however, was viewed as invariably positive and, thus, of relatively low professional value, a finding that mirrors Ahmed et al. [10]. That said, the DJs reported this fan feedback was highly useful in gauging the quality of audience experience after a live performance.

The DJs highly valued analytics where these were available (e.g. Facebook Pages and SoundCloud). These typically offer numerical track-level feedback such as likes, plays and downloads but also highlighted the geographical demographics and patterns of specific user visits.

FL: "I have 5000 plays on my SoundCloud. It's really a good tool, you have lots of statistics of things, my SoundCloud has been played in I don't know... about 50 countries, like India, your hometown I don't know... Venezuela, Argentina, the stats are very specified to that. And the fanpage on Facebook is really cool; you have access to everything. Everything! You posted a song, you can see how many plays it has, how many people see that, how many commented, liked and... everything. You can see the evolution of the fanpage on graphics... 100, 200, 2000, $3000,4000 \ldots$ The number of people that for some reason unlike your page, you also have that one."

However, meaningfully interpreting such trends was reported to be challenging and they were sometimes simply integrated into promotional activities: one DJ reported that his club tied special events to such statistics, throwing a party when they met a target for Facebook "likes".

Discovering and Learning. SNS also played a strong role in discovery of both content and tools. In terms of content, a range of practices was reported. These included monitoring online genre-specific charts, but also SNS activity such as trawling the walls and pages of other DJs. In such activities the perceived fame and influence of the DJs was an important criteria in assessing the value and worth of new tracks. It was also reported to be common practice to request specific track IDs and histories when commenting on online remixes, pinning down the sources and history of particular media content.

FL: "The really good thing (on SoundCloud) is that people can interact in the middle of the music, leave a comment on minute 52 or 53 or minute one... ok this is great, track ID that kind 
of thing... you share information on that. It's really cool because you can always follow artists that are your inspiration or influence, you see them work and if they have a DJ set that had attracted you... you really, really like, you can go there and ask for the track ID, the DJ will answer or someone from the community that is following will answer too... that's really, really cool."

In terms of tools, as mentioned earlier, DJs reported that hardware and software reviews and tutorials are widely posted on music SNS and such material was a key way to keep abreast of technical developments and innovations in the field.

Organizing and Coordinating. SNS such as Facebook were seen as a valuable tool for planning and organizing events. Beyond promotion of clubs, venues and parties via posting teaser sample content, the acceptance of event-invites and likes or comments was reported to provide valuable information on prospective attendance levels and enthusiasm for special themes. However, on the other hand, some found SNS suffering from a deluge of information about events and expressed frustration over how it was getting difficult to use for promoting local events.

H: "Nowadays its too much, too many things... people use Facebook only to see friends... like you can ask people, they don't care about the events because its too much, too many events... now its the opposite I think the best way to promote things is (by) speaking with the persons, calling up the person, giving him flyers."

\section{$5 \quad$ Issues and Concerns}

This section summarizes the wider concerns the respondents voiced about their profession. Some of these come across as issues germane to their profession that are, or have the potential to be, supported by SNS usage in some ways, whereas others serve as reflection of the perceived threats and shortcomings of existing social technologies. DJs highlighted a need to collectively tackle issues of curation, perceptions of threats about exclusivity, issues in cultivating and maintaining connections with peers, and a loss of mobility due to economic factors.

\subsection{Need for Curation}

Some of the DJs viewed themselves as curators of traditional formats on one hand and contemporary music on the other. One DJ reported how some of the older DJs like him were taking it upon themselves to preserve the analog legacy of vinyl records, citing nostalgia, sound quality and content exclusivity as legitimate drivers. Implicit in his call for this preservation was a need to collectively 'keep things alive'.

$\mathrm{H}$ : "If you go to the vinyl or the other formats you can be special... still special because so many records are released and never arrive at digital shops. So lots of people, normally more older DJs are keeping the things alive... like ok, we always say oh vinyl is going to die but no... we are the guys who have to keep it alive, we cannot be like this." 
This nostalgia also carried forward to music itself, with some of the DJs commenting on early exposure to these cultural legacies. It's worth noting how the notion of curation ties in closely with old artifacts such as 'grandfather's records' or to old mu-sic genres. One of the respondents related a DJ's role to that of a teacher with responsibilities to educate people about 'taste'.

FL: "When I was a kid, I grew up listening to my grandfather's records... Eddie Grant, Boney $M, A B B A . .$. I really have a... I really have a strong connection to the 80 s."

M: "I think that the DJs also work as a teacher. A DJ has a responsibility to have a good musical taste and to show people what good music is about. When you go to the doctor, you don't want to teach him how to fix you."

These concerns directly reflected in their sharing behavior on social networks. For example, they shared their own music on Facebook as well as music from artists or labels they liked and followed. Some of them also shared charts that they created every month on Resident Advisor. DJs who hosted radio shows would also share their playlists or podcasts later on SoundCloud and Facebook.

\subsection{Threats to Exclusivity}

Almost all the DJs expressed strong concerns about the lack of exclusivity caused by easy access to music online, especially via social networks and online music stores such as beatport.com. They perceived this as a threat to their music selection activity for performances, suggesting tensions between sharing and maintaining secrecy in their 'sources'.

MC: "Nowadays, especially nowadays when everyone is a DJ, everyone is playing music, very difficult to stand out... when I say stand out everyone is playing the same track. If I get a track on beatport I have to understand that lots of other people will have it. So I dedicate lots of time researching the tracks to get music."

M: "I don't use social networks to do my music research, I use some sites from... about music, like beatport, djdownload.com, Juno records... but mostly I use the label sites like compact, moon records... then I use some magazines / reviews, some DJ reviews."

In this context, as also noted by Ahmed et al. [10], DJs considered gifting as a valuable way to receive exclusive content. DJs who frequently shared music on their Facebook pages or had their own radio shows or podcasts regularly received large amounts of free music from other lesser-known artists who wanted exposure and feedback to their own work. One DJ commented on how his research involves more 'listening' to tracks sent to him via emails rather than looking for new artists or music on the Inter-net.

Concerns of exclusivity also overlapped with issues of professional identity. Readily available tools and equipment with more user-friendly features also brought into question the skills that defined a DJ as an entity. Some of them voiced concerns about how technology now enables anybody to assume the role of a DJ. 
F: "Everyone is a DJ nowadays. When I was young, the main thing was having a band. Everyone had a band and I was the DJ... and nowadays everyone is a DJ because it's easy. You can have an application on your iPhone to run to a speaker and be a DJ for one night or two nights."

\subsection{Connecting with Peers}

Technology also had a huge bearing on the ways in which the DJs researched and bought music changed over time. Two of the DJs who had been in the profession for more than 15 years narrated tales of how they used to buy music in the past by going through catalogues in magazines and calling up the record shops in other bigger cities. They would spend hours on the phone listening to one record after the other, as the shop owner manually played out samples of tracks. Although they valued the present day online music stores for the afforded convenience, they missed the personal recommendations and social aspects of buying music that physical record shops had.

$\mathrm{H}$ : “One thing I miss a lot is we don't have here record shops where you can go and ... that is the really social network, because every DJ is going to be there and you can be there 5-6 hours chatting, exchanging ideas that is one thing we don't have... Recently I was in Amsterdam, I spent about 5 hours in one record shop and I met 3 to 4 people I didn't know before, only because of the music... 'Oh you are going to buy this, if you like this also try this'... I think it's social, the big social thing for DJs and artists. Going to a record shop as physical space you know... everyone is going to be there and have the same passion as you... That helps a lot in actual networking."

As mentioned earlier, DJs appreciated the role SNS played in maintaining their connections with peers, fans and record label owners. However, they also experienced the problem of having to maintain profiles in multiple SNS. Facebook and SoundCloud integrated very well according to them, but in general they perceived a lack of integration between most.

G: "You cannot be everywhere, because the effect is opposite. You have to be in one or two (then) people will be interested. If you have 5 or 6 social networks, it's going to be messy. You cannot arrive to the people. If it's too big, things get too big and then you lose focus."

Additionally, they also highlighted the need to narrowcast instead of simply broadcasting; this was perceived as a problem in the current SNS.

FL: "You can record something you put it on a CD and give it in the hands of friends... Give it in their hands.. Otherwise you can record something and upload it on SoundCloud and you have the whole world accessing your files. Its very much; you can reach more people. The problem is that everyone can do it, so I am uploading and another 3 million DJs are uploading their work."

Almost all the DJs highlighted the need for some of the local DJs to come together as a small community in order to maintain a certain quality of music in the clubs in the city. Some of them even complained about how some in the city were playing 
'commercial stuff', a derogatory term in DJ-speak, in order to cater to 'younger audiences who didn't care about music'. On the other hand, they would also engage in activities showing mutual respect, for instance by visiting each other's gigs or commenting on each others' posts on Facebook, following each other and exchanging feedback on SoundCloud.

FL: "Yes we have a small community. Most of the DJs already know SoundCloud, they have an account, they have (their) work (on it) and we always share... I share, they share... I follow them, they follow me and we have a small community."

\subsection{Loss of Mobility}

DJs considered being invited to far off venues as a sign of popularity and success or as an opportunity to gain fame. However, they ascribed the current economic crisis as an impediment to mobility, their ability to travel around or be invited to big gigs, owing to the expenses involved.

$\mathrm{H}$ : "It's expensive for clubs in other cities to pay for my flights. So many times (it's) happened that they couldn't hire me because of that... because of the travel expenses. It's really hard, I need to go more and more to other places... but with that money they can hire bigger names."

In addition the local clubs also stopped inviting international DJs because of economic reasons and this, according to the DJs, adversely affected the local electronic music 'scene' since the club patrons weren't 'exposed to good stuff'.

F: "The clubs must invite international DJs... they did that a few years ago."

Some of the DJs tried to bridge these gaps through the use of SNS by sharing music from well-established international DJs on their pages or personal walls, attracting comments by fellow DJs and fans alike. DJs used SNS to follow their favorite artists and accessed their social media on sites like YouTube and SoundCloud, occasionally catching live streaming feeds of performances.

\section{Observations}

We present a brief account below of our observations about the DJs' social behaviors online and offline in order to support our findings from the interviews. DJs used SNS extensively to promote events from the clubs they held residencies in. As public faces of the clubs, their social networking blurred the lines between friends and fans, reflecting their unique role as resources for maintaining place-based social capital and as practitioners of 'micro-celebrity' [6,7].

As mentioned earlier the DJs used SNS to organize and coordinate events. Specifically, DJs engaged in a pre-event and post-event dialogue with club patrons using the Events feature on Facebook. It's interesting to note here that most of the clubs' Facebook pages were managed by the resident DJs themselves and hence they 
would be the ones responsible for creating the event page on Facebook for weekend parties and invite all the 'fans'. They would upload posters and share music videos from content communities such as YouTube or SoundCloud to offer a glimpse of the kind of music to be played.

Although a full account of the participant-observations is outside the scope of this paper, we present below a brief summary of our observations of DJs and reflexive notes from the primary author's first hand experiences playing as a DJ several times. We limit our description to the part that relates to SNS directly or indirectly.

\subsection{Friends as Audience}

Audience members who were friends of (or simply familiar with) the DJ exhibited a unique etiquette of patronage. They would display their relationship to the DJ by explicitly shaking hands, talking to them briefly or spending time standing or dancing adjacently. These individuals often acknowledged familiarity with, or appreciation of, specific tracks by various explicit gestures (nodding, raising hands, showing thumbsup). They also frequently took pictures of themselves (sometimes with the DJ), uploaded this content to SNS and tagged themselves and the venue and/or DJ.

\subsection{Audience as Friends}

Social barriers between a performer and audience members were significantly lowered when the DJ was visible and playing on the same level as the dance floor (instead of on a raised platform). Some of the DJs appreciated this openness since it allowed them to interact with club-goers who approached to ask about a track ID or show their appreciation. Such individuals frequently added the DJ as a Facebook friend in the venue (using smartphones), or simply requested the DJ's account ID. In general, these were readily provided and the process was viewed as socially appropriate (unlike requesting a phone number).

\section{Discussion}

This paper discusses how DJs use social networks in their work. A substantial body of mixed method fieldwork was carried out. The synthesized results expose the quality and detail of a range of practices from DJs promoting themselves (locally and further afield), to connecting more closely with fans, to gauging their abilities and learning and discovering content. These raise many implications for designers of music related applications, services and social systems. We discuss these implications and outline some of the design directions that emerged from our data. These directions are also aimed at demonstrating the true value of adopting an ethnographic approach for studying such an area of HCI research.

DJs are prolifically social artists adopting a wide range of different social roles. Primarily, they view themselves not just as performers but also educators, finding and defining musical trends. This role as the disseminator of new music has inherent 
tensions as their ability to set trends partly relies on their ability to spot and gain access to them ahead of the crowd - although their main business is sharing music, to be successful, their sources need to retain an element of mystery. Furthermore, they receive a wide range of public feedback on their work and need to understand and manage it carefully - fans should be supportively thanked and encouraged while peers treated with attention and respect. These tensions suggest a range of novel opportunities for design. For instance, social tools that enable improved segregation of friends or acquaintances into qualitatively different groups (such as peers and fans) would enable them to more effectively respond to feedback - allowing them to narrow-cast rather than broadcast their activities and avoid problems of "contextcollapse" [26]. Social music sites (e.g. last.fm, grooveshark.com) and personal music devices (e.g. iPod) could adopt features with a stronger emphasis on the role of curators and integrate recommendations, via charts and playlists, by local DJs.

DJs use SNS to understand their audience better (e.g. using analytics), engage in pre and post performance dialogue with them, and interact with them in nightclubs often augmenting their social capital by adding them as friends. This behavior can be supported more deeply by designing systems that allow DJs to acquire information about their audiences' preferences in music. Considering the fact that DJs 'play to the crowd' and invariably improvise their playlists [10] depending on the audience, it would be of substantial value to build systems that can offer music related meta data from the audiences' SNS profiles (e.g. artists they 'like') on an onsite 'real-time' basis to the DJ.

Beer [16], in his interview with Jarvis Cocker, observed how fans on MySpace interacted more with one another rather than with the musician, and how the presence of musician worked as a catalyst for fan-to-fan interactions. Future research can focus on understanding these phenomena better and explore the role of DJs as a catalyst for enhancing face-to-face interactions among the club patrons. Services such as Foursquare (https://foursquare.com/) that focus on such place-based social interactions can look at ways to integrate the role of place owners or inhabitants in enhancing face-to-face interaction. We observed how the audience integrated SNS with the physical venues the DJs performed in, such as photo-tagging and friendadding behaviors in clubs. One possible design direction could be to design applications that integrate the music being played at a particular moment with the photographs, allowing the audience to capture memories in more expressive ways and enabling the DJ to have real time feedback or evidence of the impact of his selection on the mood of the audience.

We believe these findings will be useful for researchers and designers working in the area of DJ-audience interaction or in the larger topics of crowd computing and designing for spectators. We also believe that insights such as those presented in this paper can serve as the foundation for designers and developers to create novel integrated SNS that support real performer and DJ practices and needs. Extending beyond DJs, these findings can also inspire design of social systems around common interests that acknowledge the role of human beings embedded in places as resources for enabling social interaction, face to face and beyond. 
A limitation of the current study is that all information about SNS is based on data reported in interviews or recorded in participant observation. A valuable extension to this work would be to build tools that capture actual SNS' network data from performers over a protracted period. This would help shed more interpretative light on the specifics of DJs' online behavior. Particular topics for attention should include how DJs use features such as Facebook Pages (and its Listen feature) or the granular commenting system on SoundCloud. As with any small study, the representativeness of the sample of DJs (a busy and relatively hard-to-access user group) observed could be called into question. Data from a larger and more diverse group, for example featuring several cities and DJs at different income brackets, would clearly add meaning and validity to the results. These issues aside, we believe this paper has exposed important aspects of how performers use SNS in their work activities. We hope this impels other authors to explore this interesting and under-researched area in the future.

Acknowledgements. This work was supported by Madeira Life, a project co-funded by the Regional Government of Madeira (MADFDR-01-0190-FEDER_001) and ZON Multimedia. We would like to thank the DJs for their participation and support.

\section{References}

1. Choe, S.H., Russell, M.: Bringing K-Pop to the West, New York Times (March 5, 2012)

2. Baym, N.K.: Fans or friends?: Seeing social media audiences as musicians do., Participations. Journal of Audience \& Reception 9(2) (2012)

3. Boyd, D.M., Ellison, N.B.: Social network sites: Definition, history, and scholarship. Journal of Computer-Mediated Communication 13(1), article 11 (2007)

4. Baym, N.K.: The new shape of online community: The example of Swedish independent music fandom. First Monday 12(8) (2007)

5. BBC News: Gangnam Style becomes YouTube's most-viewed video, http: //www.bbc.co.uk/news/technology-20483087 (retrieved on January 22, 2012)

6. Senft, T.: Camgirls: Celebrity and Community in the Age of Social Networks. Peter Lang, New York (2008)

7. Marwick, A., Boyd, D.: To See and Be Seen: Celebrity Practice on Twitter. Convergence 1(7), 125-137 (2011), doi:10.1177/1354856510394539

8. Mashable.: 5 Superb Social Media Tools for Musicians, http://mashable.com/ 2010/01/04/social-media-tools-bands (retrieved on January 22, 2012)

9. Gates, C., Subramanian, S., Gutwin, C.: DJs' perspectives on interaction and awareness in nightclubs. In: Proc. DIS 2006, pp. 70-79. ACM Press (2006)

10. Ahmed, A.Y., Benford, S., Crabtree, A.: Digging in the Crates: An Ethnographic Study of DJs' Work. In: Proc. of CHI 2012. ACM Press (2012)

11. O’Hara, K., Brown, B.: Consuming Music Together. Springer (2005)

12. Denora, T.: Music in Everyday Life, 181 p. Cambridge University Press, Cambridge (2000)

13. Brown, B., Sellen, A.J., Geelhoed, E.: Music sharing as a computer supported collaborative application. In: Proc. ECSCW (2001) 
14. Tanaka, A.: Interaction, Agency, Experience, and the Future of Music. In: Brown, B., O'Hara, K. (eds.) Consuming Music Together: Social and Collaborative Aspects of Music Consumption Technologies, vol. 35. Springer, Dordrecht (2006)

15. Goffman, E., Joel, B.: Interaction ritual: Essays in face-to-face behavior. Aldine De Gruyter (2005)

16. Beer, D.: Making friends with Jarvis Cocker: Music culture in the context of Web 2.0. Cultural Sociology 2(2), 222-241 (2008)

17. Sargent, C.L.: Local Musicians Building Global Audiences. Information, Communication \& Society 12(4), 469-487 (2009)

18. Shamma, D., Churchill, E., Bobb, N., Fukuda, M.: Spinning Online: A Case Study of Internet Broadcasting by DJs. In: Proc. C\&T 2009, pp. 175-184 (2009)

19. Benford, S., Tolmie, P., Ahmed, A.Y., Crabtree, A., Rodden, T.: Supporting Traditional Music-Making: Designing for Situated Discretion. In: Proc. CSCW 2012 (2012)

20. TechCrunch.: New "Listen" Button On Facebook Musician Pages Instantly Plays Their Songs In Your Favorite Streaming App, http: / / techcrunch.com/2012/04/17/ facebook-listen-button (retrieved on January 22, 2012)

21. Gilbert, J.: Ping Dead: Apple's iTunes Social Network Will Shut Down on September 30. Huffington Post (September 13, 2012)

22. Rode, J.A.: Reflexivity in Digital Anthropology. In: Proc. CHI 2011, pp. 123-132 (2011)

23. Johnson, R., Rogers, Y., Van Der, L.J., Bianchi-berthouze, N.: Being in the Thick of Inthe-wild Studies. In: Proc. CHI 2012. ACM Press (2012)

24. Hook, J., Green, D., McCarthy, J., Taylor, S., Wright, P., Olivier, P.: A VJ Centered Explo-ration of Expressive Interaction. In: Proc. CHI 2011. ACM Press (2011)

25. Braun, V., Clarke, V.: Using Thematic Analysis in Psychology. Qualitative Research in Psychology 3(2), 77-101 (2006)

26. Marwick, A.E.: I tweet honestly, I tweet passionately: Twitter users, context collapse, and the imagined audience. New Media \& Society 13(1), 114-133 (2011) 